Eulalia BASELGA ${ }^{1}$

May EL HACHEM ${ }^{2}$

Andrea DIOCIAIUTI ${ }^{2}$

Claudia CARNEVALE ${ }^{2}$

Camila DOWNEY ${ }^{1}$

Esther ROE ${ }^{1}$

Patricia MASCARO ${ }^{3}$

Iria NERI ${ }^{4}$

Miriam LEUZZI ${ }^{4}$

José BERNABEU-WITTEL ${ }^{5}$

Maria Teresa

MONSERRAT-GARCÍA ${ }^{5}$

Alejandro ORTIZ-PRIETO ${ }^{5}$

Antonio TORRELO ${ }^{6}$

Nicole KNOPFEL ${ }^{6}$

Nadia VERCELLINO ${ }^{7}$

Francesca MANUNZA ${ }^{7}$

Teresa ORANGES ${ }^{8}$

Andrea BASSI $^{8}$

Maria Antonia

GONZALEZ-ENSEÑAT ${ }^{9}$

Asunción VICENTE ${ }^{9}$

Ignasi GICH ${ }^{10}$

Luis PUIG ${ }^{11}$

${ }^{1}$ Paediatric Dermatology Department, Hospital de la Santa Creu i Sant Pau,

Barcelona, Spain

${ }^{2}$ Pediatric Dermatology Unit, Bambino Gesù Children's Hospital, IRCCS, Rome, Italy

${ }^{3}$ Universitat Autónoma de Barcelona,

Barcelona, Spain

${ }^{4}$ Division of Dermatology, Department of Experimental, Diagnostic and Specialty

Medicine, University of Bologna, Bologna,

Italy

${ }^{5}$ Hospital Universitario Virgen del Rocío,

Sevilla, Spain

${ }^{6}$ Hospital del Nino Jesus, Madrid, Spain

${ }^{7}$ Dermatology Unit and Angioma Center, IRCCS Istituto Giannina Gaslini, Genoa,

Italy

${ }^{8}$ Department of Health Sciences, Anna

Meyer Children's University Hospital,

Florence, Italy

${ }^{9}$ Department of Dermatology, Hospital Sant

Joan de Déu, Barcelona, Spain

${ }^{10}$ Epidemiologia Clínica, CIM - Caiber - IIb

Sant Pau, Barcelona, Spain

${ }^{11}$ Dermatology Department, Hospital de la

Santa Creu y Sant Pau, Barcelona, Spain

Reprints: Eulalia Baselga

<dra.baselga@gmail.com>

Article accepted on 24/02/2021

\section{Sequelae following infantile haemangiomas treated with propranolol}

Background: Oral propranolol accelerates the involution of infantile haemangiomas (IHs). However, it is not clear whether IHs treated with oral propranolol are associated with fewer sequelae than when left untreated. Objectives: To quantify and describe sequelae associated with IHs treated with oral propranolol, and to explore whether treated IHs are associated with fewer sequelae than untreated IHs. Materials \& Methods: This multicentre, retrospective, cohort study included patients with IH treated with oral propranolol $\geq 2 \mathrm{mg} / \mathrm{kg}$ for at least six months, with photographic images available at baseline and at age 4-5 years. A historical comparison cohort comprised 185 patients with untreated IHs. Main outcomes/measures were: IH features, treatment characteristics and type/degree of sequelae. Results: Oral propranolol, most commonly at $2 \mathrm{mg} / \mathrm{kg} /$ day (mean duration: nine months), was initiated in 171 patients (mean age: 6.02 months). After treatment, 125 of $171(73.1 \%)$ IHs were associated with no/minimal sequelae. The most common sequelae were telangiectasia (78\%), fibrofatty tissue (37\%) and anetodermic skin $(28 \%)$. Deep IHs were associated with significantly fewer sequelae than other subtypes. Ulceration appeared to increase the likelihood of severe sequelae. IHs with a stepped border was associated with more severe sequelae than those with a progressive border (44\% versus $27 \%$, $p<0.05)$. Treated IHs resolved without sequelae or were associated with a sequela that did not need correction in $27.7 \%$ more cases than untreated IHs (RR: $1.61 ; p<0.001)$. Conclusion: Among IHs treated with oral propranolol, $73 \%$ resolved without, or were associated with minimal sequelae. Deep IHs were associated fewer sequelae than other subtypes. Oral propranolol decreased the likelihood of $\mathrm{IH}$ sequelae requiring correction

Key words: infantile haemangioma, propranolol, sequelae
I nfantile haemangiomas (IHs) are the most common vascular tumour of infancy, occurring in up to $5 \%$ of infants [1]. Most resolve spontaneously over time, usually by three to five years of age [2-5]. However, up to $10 \%$ of IHs may require treatment because they are lifethreatening or at risk of complications, such as ulceration, functional impairment, or long-term or permanent cosmetic disfigurement [5-7].

The treatment of IHs should be individualized, after considering the potential risks and benefits $[8,9]$. The decision to treat may be clear-cut for IHs that may affect the airway, eyesight, or liver (with the potential risk of cardiac failure), or for those at risk of ulceration, however, it may be more difficult if the main concern is cosmetic disfigurement [6]. Possible sequelae after involution of IHs include telangiectasia, redundant or anetodermic skin, fibrofatty tissue and scarring $[2,4,10]$. Despite the well-known self-involutive nature of most IHs, it has been reported that if untreated, more than $50 \%$ of IHs will leave significant residual lesions $[2,4]$. 
Oral propranolol is the mainstay of medical treatment for IH $[5,7,9,11]$. It accelerates the regression of IHs, with $60 \%$ of treated IHs resolving completely after six months of treatment [12], and $76 \%$ if treatment is extended up to 12 months of age [13]. However, it is not clear whether propranolol only accelerates IH involution, or whether it also improves outcomes in terms of reducing the risk of sequelae. If the end result regarding sequelae is likely to be the same, some parents might prefer to wait for spontaneous involution of IHs rather than have their child undergo treatment with oral propranolol.

To test the hypothesis that IHs treated with oral propranolol are associated with fewer sequelae than untreated IHs, a retrospective analysis was undertaken to quantify and describe the type of sequelae associated with treated IHs, to identify correlations between the type or degree of sequelae and $\mathrm{IH}$ characteristics, and to explore whether treated IHs could leave fewer sequelae than untreated IHs.

\section{Materials and methods}

The study involved a retrospective review of photographic images taken from 2008 to 2012 for patients with IH treated with oral propranolol at nine hospitals in Spain and Italy. Patients had to have received systemic treatment with propranolol at a dose of at least $2 \mathrm{mg} / \mathrm{kg}$ for at least six months, with available photographs taken at baseline and between the ages of four and five years. Patients were excluded if they had participated in clinical trial V00400SB201 (a worldwide study comparing several propranolol regimens with placebo for $\mathrm{IH}$ ) which was ongoing during the period 2010-2013.

Centres obtained approval for the study from the relevant institutional review boards. For those patients who were still being managed at participating clinics or who were contactable by telephone, written informed consent was obtained from parents or legal guardians. For patients who were no longer contactable, previous consent to keep photographs for later review was obtained. No compensation was given to patients/parents for participation in the study. Study data were collected and managed using the REDCap electronic data capture tools hosted at Hospital de la Santa Creu i Sant Pau, Barcelona, Spain. The following data were collected: demographics; IH location and size, morphology (focal, segmental, indeterminate), subtype (superficial, deep, mixed, abortive [minimally proliferative $\mathrm{IH}]$ ), border/thickness of the superficial component (stepped/thick, smooth/progressive) (figure 1); treatment characteristics; degree of sequelae (no sequelae, minimal sequelae not needing correction or needing only laser for residual telangiectasia or colour, sequalae needing surgery) (figure 2); and type of sequelae (telangiectasia, anetodermic skin, redundant skin, fibrofatty tissue, scar, anatomic distortion, alopecia, others). IH characteristics and the type of sequelae were based on analysis of photographs taken prior to treatment (baseline) and at age 4-5 years (after treatment with systemic propranolol). All cases were reviewed by the same investigator (EB).

Data for patients treated with oral propranolol were compared with data for untreated patients from a prior study that evaluated sequelae after natural involution of untreated IHs [4]. The latter study was performed using the same REDCap data capture program.

Statistical analysis was performed at Hospital de la Santa Creu i Sant Pau. Logistic regression was used to assess potential predictive factors for sequelae (none/minimal sequelae vs significant/severe sequelae). Odds ratios (OR) with corresponding $95 \%$ CIs and $p$ values were calculated. The $\chi 2$ test was used for categorical variables. To study the correlation and dependence of variables, we used the Spearman correlation coefficient, Mann-Whitney test, and Kruskal-Wallis. All statistical analyses were performed using IBM-SPSS statistical software (version 25, SPSS Inc).

\section{Results}

A total of 171 patients treated with oral propranolol were included in the study; 126 females $(73.7 \%)$ and 45 males. The clinical characteristics of the 171 IHs are summarized in table 1. The most common locations were the head and neck $(83 \%)$. The most common morphological type was focal $\mathrm{IH}(51 \%)$, and the most common subtype was mixed IH (48\%). Most IHs (73\%) had a smooth/progressive border of the superficial component.

Propranolol treatment was initiated at a mean age of 6.02 months (range: 1.22-21.81) and was administered for a mean duration of nine months. The most common dose was $2 \mathrm{mg} / \mathrm{kg} /$ day (range: $2-4 \mathrm{mg} / \mathrm{kg} /$ day).
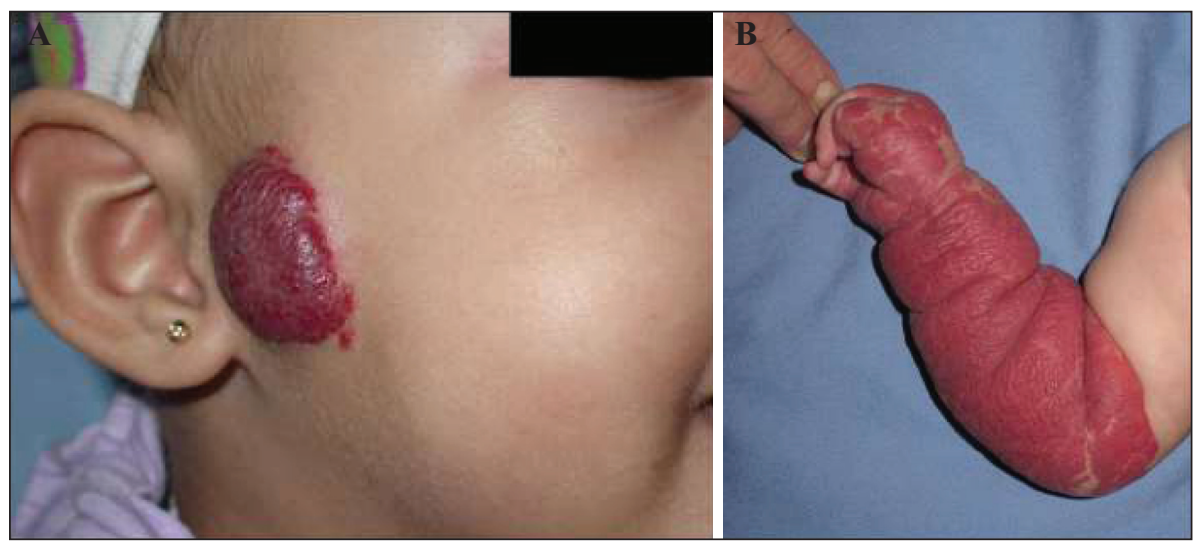

Figure 1. Examples of different thicknesses of the superficial component: stepped/thick (A) and smooth/progressive (B). 


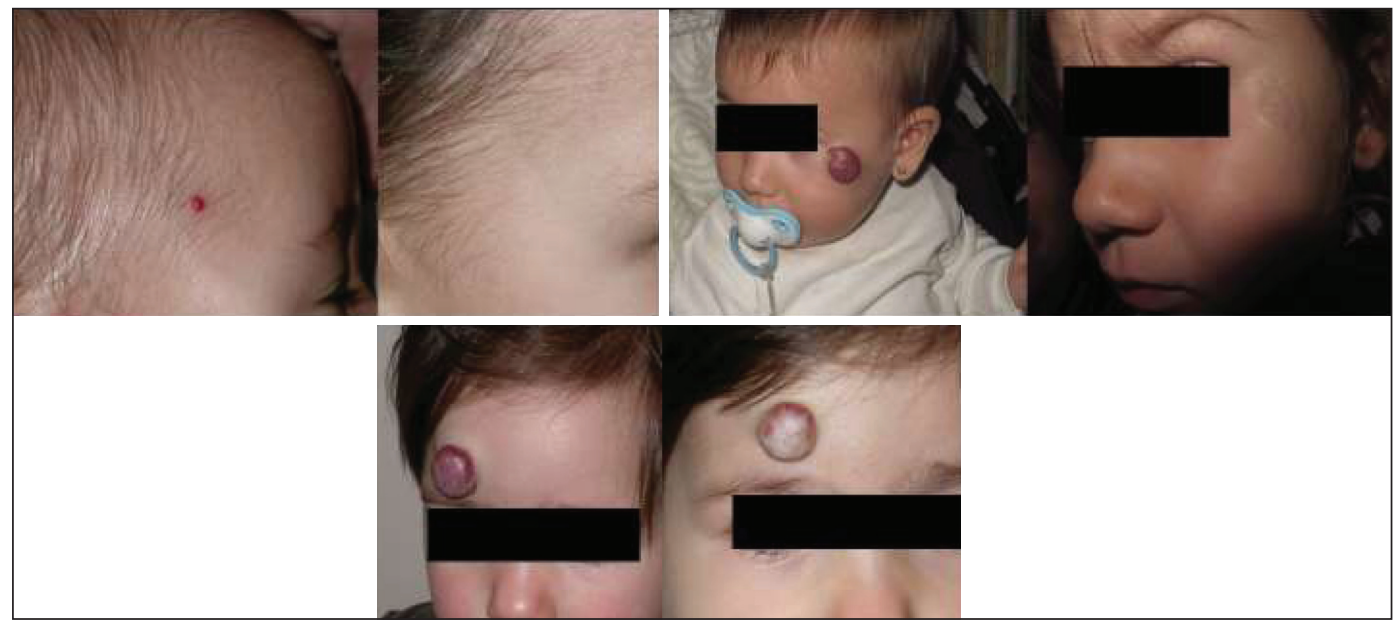

Figure 2. Examples of the degree of sequelae: none (upper left panel), present but not needing correction (upper right panel), severe/needing correction (lower panel).

Table 1. Clinical characteristics and sequelae of the infantile haemangiomas (IHs).

\begin{tabular}{|ll|}
\hline Characteristic & Number (\%) \\
\hline Total number of IHs & 171 \\
\hline IH location & \\
$\quad$ Head and neck & $142(83.0)$ \\
\hline IH morphology & \\
Focal & $87(51)$ \\
Segmental & $41(24)$ \\
Indeterminate & $43(25)$ \\
\hline IH subtype & \\
Superficial & $46(27)$ \\
Deep & $33(19)$ \\
Mixed & $82(48)$ \\
Abortive or minimally proliferative IH & $10(6)$ \\
\hline Border/thickness of superficial component & \\
Stepped/thick & $46(27)$ \\
Smooth/progressive & $125(73)$ \\
\hline Diameter in mm (mean \pm sd) & $19.8 \pm 35.6$ \\
\hline Degree of sequelae & \\
None & $27(15.8)$ \\
Present but minimal/not needing correction & $98(57.3)$ \\
Severe/needing correction & $46(26.9)$ \\
Reconstructive surgery & $20(11.7)^{\mathrm{a}}$ \\
Excisional surgery & $29(17.0)^{\mathrm{a}}$ \\
\hline Type of sequelae & \\
Telangiectasia & $113(78)$ \\
Anetodermic skin & $40(28)$ \\
Redundant skin & $14(10)$ \\
Fibrofatty tissue & $54(37)$ \\
Scar & $29(20)$ \\
Anatomic distortion & $36(25)$ \\
Alopecia & $4(3)$ \\
Other & $4(3)$ \\
\hline
\end{tabular}

${ }^{a}$ The total for reconstructive and excisional surgery adds up to more than 46 because some patients required both excisional and reconstructive surgery.

After treatment with propranolol, 125 of $171(73.1 \%)$ had no sequelae or sequelae not needing correction, while 46 of $171(26.9 \%)$ IHs had sequelae needing correction (table 1$)$. The most common types of sequelae were telangiectasia (78\%), fibrofatty tissue (37\%) and anetodermic skin (28\%).
IH morphology had no statistically significant effect on the degree of sequelae, although focal IHs appeared to be associated more frequently with sequelae needing surgery compared with segmental and indeterminate IHs (table 2). In contrast, the subtype of IH was associated with the degree of sequelae. Deep lesions were associated with significantly fewer sequelae compared with other subtypes (table 2). No sequelae were observed in 17 of $32(53 \%)$ deep IHs, compared with 2 of $11(18 \%)$ abortive IHs, 6 of $82(7 \%)$ mixed IHs and 2 of $46(4 \%)$ superficial lesions $(p<0.001)$. Evaluation of abortive or minimally proliferative, superficial and mixed IHs, stratified according to the presence/absence of ulceration, showed that ulceration increased the likelihood of sequelae needing surgery, particularly for superficial IHs $(p=0.02)$ (table 2).

Concerning IHs with a superficial component, the type of border was also significantly associated with the degree of sequelae (table 2); 19 of 43 (44\%) IHs with a thick superficial component (stepped border) were associated with sequelae needing surgery compared with 23 of $85(27 \%)$ of those with a progressive (smooth) border $(p<0.05)$.

Data from the treated cohort (i.e. 171 patients treated with oral propranolol) were compared with data from a historical cohort of patients with untreated IHs $(n=185)$ [4]. The distribution of IH subtypes and the degree of sequelae observed for the different subtypes are summarized in table 3 . The untreated cohort had more superficial IHs (76 of 185; 41\%) than the treated cohort (46 of $171 ; 27 \% ; p<0.001)$. There was no difference in the mean size of IHs. IHs treated with oral propranolol resolved without sequelae or were associated with a sequela that did not need correction in $27.7 \%$ more cases than untreated IHs (relative risk [RR]: 1.61; $p<0.001$ ). Mixed IHs resolved without sequelae or with sequelae that did not need correction in $62.2 \%$ and $30.9 \%$ of treated and untreated cases, respectively (table 3 ).

\section{Discussion}

The incidence and characteristics of sequelae after involution of IHs have not been well characterized. Our study expands the current body of evidence, showing that among 
Table 2. Sequelae according to infantile haemangioma (IH) characteristics.

\begin{tabular}{|c|c|c|c|c|}
\hline & $\begin{array}{l}\text { Sequelae: correction } \\
\text { needed }\end{array}$ & $\begin{array}{l}\text { Sequelae: no } \\
\text { correction needed }\end{array}$ & No sequelae & $p$ \\
\hline All IHs & $46(27)$ & $98(57)$ & $27(16)$ & \\
\hline IH morphology & & 4 & & \\
\hline Focal $(n=87)$ & $28(32)$ & $7(54)$ & $12(14)$ & NS \\
\hline Segmental $(n=43)$ & $8(19)$ & $31(72)$ & $4(9)$ & \\
\hline Indeterminate $(n=41)$ & $10(24)$ & $20(49)$ & $11(27)$ & \\
\hline \multicolumn{5}{|l|}{ IH subtype } \\
\hline Superficial $(n=46)$ & $11(24)$ & $33(72)$ & $2(4)$ & $<0.001$ \\
\hline Deep $(n=32)$ & $3(9)$ & $12(38)$ & $17(53)$ & \\
\hline Mixed $(n=82)$ & $31(38)$ & $45(55)$ & $6(7)$ & \\
\hline Abortive $(n=11)$ & $1(9)$ & $8(73)$ & $2(18)$ & \\
\hline \multicolumn{5}{|l|}{ Ulceration $^{\mathrm{a}}$} \\
\hline Superficial, ulcerated at any time $(n=11)$ & $7(64)$ & $4(36)$ & $0(0)$ & NA \\
\hline Superficial, never ulcerated $(n=35)$ & $4(11)$ & $29(83)$ & $2(6)$ & \\
\hline Mixed, ulcerated at any time $(n=19)$ & $10(53)$ & $9(47)$ & $0(0)$ & \\
\hline Mixed, never ulcerated $(n=63)$ & $21(33)$ & $36(57)$ & $6(10)$ & \\
\hline \multicolumn{5}{|l|}{ Thickness of superficial component } \\
\hline Stepped border $(n=43)$ & $19(44)$ & $24(56)$ & $0(0)$ & $<0.05$ \\
\hline Progressive border $(n=85)$ & $23(27)$ & $54(63)$ & $8(9)$ & \\
\hline
\end{tabular}

Data are presented as number (\%) of patients (\% of the relevant subgroup). ${ }^{a}$ Infantile haemangioma subtype ( superficial, $n=46 ;$ mixed, $n=82$ ) according to presence/absence of ulceration.NA: not available; NS: not statistically significant.

Table 3. Comparison of treated and untreated ${ }^{\mathrm{a}}$ infantile haemangiomas (IHs).

\begin{tabular}{|c|c|c|c|c|c|c|c|}
\hline IH subtype & \multicolumn{3}{|c|}{ Propranolol treatment $(n=171)$} & \multicolumn{3}{|c|}{ No treatment $(n=185)$} & $\frac{p^{\mathbf{b}}}{0.001}$ \\
\hline Superficial & \multirow{4}{*}{\multicolumn{3}{|c|}{$\begin{array}{l}46(27) \\
33(19) \\
82(48) \\
10(6)\end{array}$}} & \multirow{4}{*}{\multicolumn{3}{|c|}{$\begin{array}{l}76(41) \\
27(15) \\
81(44) \\
1(0)\end{array}$}} & \\
\hline Deep & & & & & & & \\
\hline Mixed & & & & & & & \\
\hline \multirow[t]{2}{*}{ Abortive } & & & & & & & \\
\hline & \multicolumn{3}{|c|}{ Propranolol treatment $(n=171)$} & \multicolumn{3}{|c|}{ No treatment $(n=185)$} & \\
\hline $\begin{array}{l}\text { Sequelae by IH } \\
\text { subtype }\end{array}$ & $\begin{array}{l}\text { Sequelae: } \\
\text { correction } \\
\text { needed }\end{array}$ & $\begin{array}{l}\text { Sequelae: no } \\
\text { correction } \\
\text { needed }\end{array}$ & No sequelae & $\begin{array}{l}\text { Sequelae: } \\
\text { correction } \\
\text { needed }\end{array}$ & $\begin{array}{l}\text { Sequelae: no } \\
\text { correction } \\
\text { needed }\end{array}$ & No sequelae & \\
\hline Superficial & $11(24)$ & $33(72)$ & $2(4)$ & $31(32)$ & $38(50)$ & $7(9)$ & $<0.001$ \\
\hline Deep & $3(9)$ & $12(38)$ & $17(53)$ & $14(52)$ & $8(30)$ & $5(18)$ & \\
\hline Mixed & $31(38)$ & $45(55)$ & $6(7)$ & $56(79)$ & $24(34)$ & $1(1)$ & \\
\hline Abortive & $1(9)$ & $8(73)$ & $2(18)$ & $0(0)$ & $1(100)$ & $0(0)$ & \\
\hline
\end{tabular}

Data presented as number (\%) of patients. ${ }^{a}$ Data for the "No treatment" group were derived from a study on the sequelae after natural involution of untreated infantile haemangiomas which was performed using the same REDCap data capture program [4]. ${ }^{2}$ test.

IHs treated with oral propranolol, $73.1 \%$ resolved without sequelae or were associated with sequelae that did not need correction.

The incidence of severe sequelae in our study is somewhat higher than that reported in a recent study of 73 Chinese patients (mean age at initiation of therapy: 3.8 months) with IHs treated with oral propranolol for an average of 8.3 months. Among these younger patients than ours, $16.2 \%$ left a severe residual lesion (defined as per- manent deformity of normal anatomical landmarks) [14]. Although the mean duration of oral propranolol treatment was similar between the two studies (approximately nine months), the difference may reflect the earlier initiation of treatment in the Chinese study. Consequently, the incidence of sequelae would be expected to be higher in our study. Despite a current lack of data supporting a specific threshold for propranolol initiation, initiating oral propranolol at an earlier age and for a longer duration 
should reduce the frequency of severe sequelae; ongoing research is aiming to address these concepts to improve the indication for treatment. Nevertheless, the incidence of severe sequelae after systemic propranolol treatment in both studies is substantially lower than that reported for untreated IHs. A multicentre study of 185 untreated IHs (coordinated by our centre) found that $55 \%$ were associated with significant/severe sequelae after natural involution [4]. Comparison of data from the current study with data from the study of untreated IHs indicated that oral propranolol treatment reduced the risk of the occurrence of sequelae needing correction (RR: 0.49), with mixed IHs appearing to benefit the most from oral propranolol treatment. Similarly, in a retrospective study of 420 patients with $\mathrm{IH}$, Coulie et al. showed that $36.8 \%$ of untreated patients still required surgical correction of sequelae versus $7.8 \%$ when initially treated with oral propranolol [15]. Comparison between treated with untreated IHs is probably subject to selection bias as it is more likely that larger or more severe IHs received treatment and, therefore, the favourable outcome in the treatment group could be even higher.

The most common sequelae observed in the current study were telangiectasia and fibrofatty tissue. This is consistent with the findings of other studies concerning oral propranolol treatment or following the natural involution of untreated IHs, where telangiectasia and fibrofatty tissue are the most common types of sequelae $[2,4,14]$.

Deep IHs were associated with fewer sequelae than other types of IHs in the current study. This is consistent with the study by Yu et al., which found significantly more sequelae in superficial IHs than in deep lesions after propranolol treatment $(83.4 \%$ versus $20 \%, p<0.05)$; the difference between superficial and mixed IHs (72.5\%) did not achieve statistical significance [14]. In one study of untreated IHs, more sequelae with superficial nodular IHs than deep nodular lesions were reported (74\% versus 25\%, $p<0.001$ ) [2], while another found that mixed IHs were associated with more severe sequelae than superficial and deep lesions (OR: 3.3; 95\% CI: $1.7-6.3 ; p<0.001$ and OR: $2.1 ; 95 \%$ CI: $0.9-5.1 ; p<0.001$, respectively) [4].

In the current study, analysis of superficial and mixed IHs suggests that previous ulceration increases the risk of sequelae needing surgical correction. It is recognized that ulceration is inevitably associated with scarring $[4,6,16]$. In a study of untreated IHs, residual lesions (usually atrophic scarring) occurred in 29 of 30 ulcerated, infected and bleeding IHs (97\%) [2]. It was also found that among IHs with a superficial component, those with a stepped border were more likely to leave severe sequelae than those with a progressive border. This was also seen in a study of untreated IHs, in which the OR for developing significant/severe sequelae was 5.76 (95\% CI: 2.6-12.8) for a steep/abrupt border compared with a smooth/progressive border [4].

This study has several limitations. It is a retrospective study without systematic follow-up of IHs. Photographs were used for measurements and analyses, and visual assessment of lesion parameters, such as border height, might not have been exact, and it is possible that IHs continued to change after final photographs had been taken at four years of age. Additionally, selection bias may have occurred, because small IHs may be less likely to be photographed than larger lesions and are more likely to be lost to follow-up. Finally, the population was not homogeneous with regard to the age of initiation of oral propranolol (mean age: six months, ranging from 1.22 to 21.81 months).

In conclusion, this study found that $73 \%$ of IHs treated with systemic propranolol resolved without sequelae or were associated with sequelae that did not require surgery. Deep lesions were associated with fewer sequelae compared to other IH types. In addition, involuting IHs which resolved without sequelae or associated with sequelae not needing correction were $27.7 \%$ more frequent in patients treated with oral propranolol than in untreated patients (RR: 1.61). This information may help clinicians and parents when making decisions about treatment for IHs.

Disclosures. Conflicts of interest: E. Baselga, M. El Hachem, and A. Torrelo received fees from Pierre Fabre Dermatologie. All other authors have no conflicts of interest to disclose.

Funding sources: This investigator initiated study was sponsored by Dr Eulalia Baselga. The study received the support of Pierre Fabre Dermatologie.

Additional Contributions: The authors thank David P. Figgitt PhD, ISMPP CMPP ${ }^{\mathrm{TM}}$, and Kathy Croom, Content Ed Net, for providing editorial assistance with the manuscript, which was funded by Pierre Fabre Dermatologie, Lavaur, France. The authors thank the patients and their parents/legal guardians for granting permission to publish information and photographs associated with this study.

\section{References}

1. Munden A, Butschek R, Tom WL, et al. Prospective study of infantile haemangiomas: incidence, clinical characteristics and association with placental anomalies. Br J Dermatol 2014; 170: 907-13.

2. Bauland CG, Lüning $T H$, Smit JM, Zeebregts $C J$, Spauwen $P H$. Untreated hemangiomas: growth pattern and residual lesions. Plast Reconstr Surg 2011; 127: 1643-8.

3. Couto RA, Maclellan RA, Zurakowski D, Greene AK. Infantile hemangioma: clinical assessment of the involuting phase and implications for management. Plast Reconstr Surg 2012;130: 619-24.

4. Baselga $E$, Roe $E$, Coulie J, et al. Risk factors for degree and type of sequelae after involution of untreated hemangiomas of infancy. JAMA Dermatol 2016; 152: 1239-43.

5. Léauté-Labrèze $\mathrm{C}$, Harper Jl, Hoeger PH. Infantile haemangioma. Lancet 2017; 390: 85-94.

6. Luu $M$, Frieden IJ. Haemangioma: clinical course, complications and management. Br J Dermatol 2013; 169: 20-30.

7. Hoeger PH, Harper Jl, Baselga $\mathrm{E}$, et al. Treatment of infantile haemangiomas: recommendations of a European expert group. Eur J Pediatr 2015; 174: 855-65.

8. Baselga Torres E, Bernabéu Wittel J, van Esso Arbolave DL, et al. Spanish consensus on infantile haemangioma. An Pediatr (Barc) 2016; 85: 256-65.

9. Darrow DH, Greene AK, Mancini AJ, Nopper AJ. Section on dermatology, section on otolaryngology-head \& neck surgery, and section on plastic surgery. Diagnosis and management of infantile hemangioma: executive summary. Pediatrics 2015; 136:786-91

10. Cheng CE, Friedlander SF. Infantile hemangiomas, complications and treatments. Semin Cutan Med Surg 2016; 35: 108-16. 
11. Krowchuk DP, Frieden IJ, Mancini AJ, et al. Clinical practice guideline for the management of infantile hemangiomas. Pediatrics 2019; 143: e20183475

12. Léauté-Labrèze $C$, Hoeger $P$, Mazereeuw-Hautier J, et al. A randomized, controlled trial of oral propranolol in infantile hemangioma. N Engl J Med 2015; 372: 735-46.

13. Baselga $E$, Dembowska-Baginska B, Przewratil $P$, et al. Efficacy of propranolol between 6 and 12 months of age in high-risk infantile hemangioma. Pediatrics 2018; 142: e20173866.
14. Yu Z, Cai R, Chang $L$, et al. Clinical and radiological outcomes of infantile hemangioma treated with oral propranolol: a long-term followup study. J Dermatol 2019; 46: 376-82.

15. Coulie J, Coyette M, Moniotte S, Bataille AC, Boon LM. Has propranolol eradicated the need for surgery in the management of infantile hemangioma? Plast Reconstr Surg 2015; 136: 154.

16. Chamlin SL, Haggstrom AN, Drolet BA, et al. Multicenter prospective study of ulcerated hemangiomas. J Pediatr 2007; 151:684$689 \mathrm{el}$. 